\title{
Yoğun Bakım Hastalarından İzole Edilen Çoklu Antibiyotik Dirençli Acinetobacter baumannii İzolatlarında Seftolozan-Tazobaktamın Çeşitli Antibiyotik Kombinasyonları ile İn Vitro Etkinliğinin Araştırılması
}

\author{
In-vitro Activity of Ceftolozane-Tazobactam in Combination \\ with Various Antibiotics Against Multidrug-resistant \\ Acinetobacter baumannii Isolated from Intensive Care Patients
}

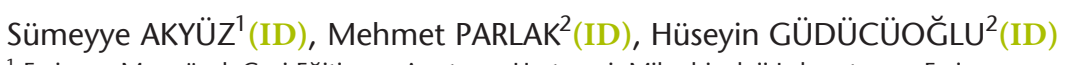 \\ ${ }^{1}$ Erzincan Mengücek Gazi Eğitim ve Araştırma Hastanesi, Mikrobiyoloji Laboratuvarı, Erzincan. \\ ${ }^{1}$ Erzincan Mengucek Gazi Training and Research Hospital, Microbiology Laboratory, Erzincan, Turkey. \\ ${ }^{2}$ Van Yüzüncü Yıl Üniversitesi Tıp Fakültesi, Tıbbi Mikrobiyoloji Anabilim Dalı, Van. \\ ${ }^{2}$ Van Yuzuncu YIl University Faculty of Medicine, Department of Medical Microbiology, Van, Turkey.
}

\footnotetext{
* Bu çalışma, Van Yüzüncü Yıl Üniversitesi Bilimsel Araştırmalar Proje Başkanlığı Araştırma Fonu tarafından desteklenmiştir (Proje No: TTU-2017-5704).
}

Makale Atıfı: Akyüz S, Parlak M, Güdücüoğlu H. Yoğun bakım hastalarından izole edilen çoklu antibiyotik dirençli Acinetobacter baumannii izolatlarında seftolozan-tazobaktamın çeşitli antibiyotik kombinasyonları ile in vitro etkinliğinin araştırılması. Mikrobiyol Bul 2020;54(1):154-162.

Öz

Acinetobacter türleri yoğun bakım ünitelerinde veya servislerde yatan immün sistemi baskılanmış hastalarda nozokomiyal enfeksiyonlara neden olmaktadır. Acinetobacter baumannii, birçok antibiyotiğe intrensek dirençli olması ve sonradan direnç geliştirebilmesi nedeniyle tedavisinde zorluk yaşanan bir bakteridir. Bu durum mevcut antibiyotiklerin kullanımını kısıtlamakta, klinisyeni yeni ilaçlara, farklı tedavi seçeneklerine ve çeşitli antibiyotik kombinasyonlarına yönlendirmektedir. Bu çalışmanın amacı, yoğun bakım ünitelerinde yatan hastalardan izole edilen çok ilaca dirençli A.baumannii izolatlarında; doripenem (DOR), tigesiklin (TGC), minosiklin (MIN), amikasin (AK) ve yeni geliştirilen bir ilaç olan seftolozan-tazobaktam (CT)'ın duyarlılı̆ını antibiyotik gradiyent test yöntemiyle belirlemek, sonrasında ise CT/DOR, $\mathrm{CT} / \mathrm{TGC}, \mathrm{CT} / \mathrm{MIN}$ ve CT/AK kombinasyonlarının in vitro etkileşimlerini antibiyotik gradiyent test yöntemiyle araştırmaktır. Hastanemizde Ocak 2017-Temmuz 2017 tarihleri arasında çeşitli klinik örneklerden (kan, idrar, balgam, trakeal aspirat, yara, apse ve kateter) izole edilen 35 A.baumannii izolatı çalışmaya alınmıştır. Bu izolatlar, yoğun bakım ünitelerinde yatmakta olan hastalardan elde edilmiş ve en az üç antibiyotik sınıfına direnç gösteren bakteriler arasından seçilmiştir. A.baumannii izolatlarının tanımlanması ve rutin antibiyotik duyarlılık profilinin belirlenmesi BD Phoenix 100 (Becton Dickinson, ABD) otomatize sistemi ile EUCAST 2017 önerileri doğrultusunda gerçekleştirilmiştir. A.baumannii izolatlarına karşı CT, DOR, TGC, MIN ve AK'ın hem tek başına hem de CT'nin diğer dört antibiyotikle ikili kombinasyonlarının 
(CT/DOR, CT/TGC, CT/MIN ve CT/AK) minimum inhibitör konsantrasyonu değerleri antibiyotik gradiyent test yöntemiyle belirlenmiştir. Kombinasyonların etkileşimlerinin in vitro olarak belirlenmesinde fraksiyonel inhibitör konsantrasyon indeksi (FiKi) kullanılmıştır. Elde edilen verilere göre; FiKi $\leq 0.5$ ise sinerjik, $0.5>$ FiKi $\leq 1$ ise aditif, $1<$ FiKi $<2$ ise indiferan (tanımlanamayan etkileşim) ve FiKi $\geq 2$ ise antagonist etkileşim olarak değerlendirilmiştir. Antibiyotik kombinasyonlarının Fiki sonuçlarına göre en yüksek sinerjik etkileşim \%11.4 oranla CT/TGC arasında gözlenmiştir. CT/DOR antibiyotikleri arasında ise sinerjik etkileşim gözlenmemiştir. En yüksek aditif etkileşim oranları CT/AK (\%60) ve CT/MIN (\%45.7) arasında görülürken, CT/DOR arasında aditif etkileşim gözlenmemiştir. Antagonist etkileşim sadece CT/DOR (\%71.4) kombinasyonunda gözlenmiş̧ir. Sonuç olarak çalışmamızda; yeni bir beta-laktam/beta-laktamaz inhibitörü olan $\mathrm{CT}^{\prime}$ nin tek başına A.baumannii izolatlarına yeterli etki etmediği ancak TGC, AK ve MIN ile kombine kullanımı halinde sinerjik etkileşim oluşturabildiği görülmüştür. $C T$, doripenem ile saptanan antagonist etkileşimi nedeniyle klinik kullanımda dikkatle izlenmelidir.

Anahtar kelimeler: Acinetobacter baumannii; çoklu ilaç direnci; seftolozan-tazobaktam; kombine ilaç tedavisi; sinerji.

\section{ABSTRACT}

Acinetobacter species lead to nosocomial infections in immunocompromised patients hospitalized in intensive care units or services. Acinetobacter baumannii is a bacterium that is difficult to treat because it is intrinsically resistant to many antibiotics and can develop resistance afterwards. This situation limits the use of existing antibiotics and directs the clinician to new agents, different treatment options and the use of various antibiotic combinations. The aim of this study was to determine the sensitivities of doripenem (DOR), tigecycline (TGC), minocycline (MIN), amikacin (AK) and a newly developed agent ceftolozane-tazobactam (CT) in multidrug resistant A.baumannii strains which were isolated from inpatients in intensive care units and to investigate the in vitro interactions of CT/DOR, CT/TGC, CT/MIN and $\mathrm{CT} / \mathrm{AK}$ combinations by using antibiotic gradient test method. Thirty-five A.baumannii strains isolated from various clinical specimens (blood, urine, sputum, tracheal aspirate, wound, abscess and catheter) between January 2017 and July 2017 were included in the study. Strains isolated from inpatients in intensive care units and resistant to at least three antibiotic classes were selected. The identification of A.baumannii isolates and the determination of routine antibiotic susceptibility profile were performed according to EUCAST 2017 criteria by the use of BD Phoenix 100 (Becton Dickinson, USA) automated system. Minimum inhibitor concentration values of CT, DOR, TGC, MIN, AK and combinations of CT with four other antibiotics (CT/DOR, CT/TGC, CT/MIN and CT/AK) were determined by antibiotic gradient test method. Fractional inhibitor concentration index $(\mathrm{FICl})$ was used to determine the interactions of the combinations in vitro. According to the data obtained; the $\mathrm{FICl}$ was evaluated as synergy if $\mathrm{FICl} \leq 0.5$, additive if $0.5>\mathrm{FICl} \leq 1$, indifferent (unidentified interaction) if $1<\mathrm{FICl}<2$ and antagonist interaction if $\mathrm{FICl} \geq 2$. According to $\mathrm{FICl}$ results of the antibiotic combinations, the highest synergistic interaction was observed between CT/TGC as $11.4 \%$. No synergistic interaction was observed between CT/DOR antibiotics. The highest additive interaction rates were between CT/AK (60\%) and CT/MIN (45.7\%), while no additive interaction between CT/DOR was observed. Antagonist interaction was observed in CT/DOR (71.4\%) combination only. In conclusion, in our study it was observed that CT, a novel beta-lactam/ beta-lactamase inhibitor, did not sufficiently affect A.baumannii isolates, but was able to induce synergistic interaction in combination with TGC, AK and MIN. CT should be carefully monitored in clinical use because of the antagonist interaction detected with DOR.

Keywords: Acinetobacter baumannii; multidrug resistance; ceftolozane-tazobactam; combined drug therapy; synergy.

\section{Giriş}

Acinetobacter cinsi içinde enfeksiyon etkeni olarak en sık saptanan tür olan Acinetobacter baumannii, yoğun bakım ünitesi (YBÜ)'nde yatan hastalarda ciddi enfeksiyonlara 
neden olan fırsatçı bir patojendir ${ }^{1}$. Tedavide geniş spektrumlu antibiyotiklerin kullanılması mevcut tedavi seçeneklerine çoklu direnci beraberinde getirmektedir. Çok ilaca dirençli (ÇiD) A.baumannii enfeksiyonlarının tedavisinde karbapenemler ve tigesiklin (TGC) kullanılabilmektedir. ÇiD izolatlarının artışı yeni tedavi rejimlerine olan ihtiyacı artırmaktadır. Yapılabilecekler arasında kombine antibiyotik tedavileri ve yeni antimikrobiyallerin üretimi sayılabilmektedir ${ }^{2}$. Ciddi A.baumannii enfeksiyonlarında morbidite ve mortalite nedeniyle kombinasyon tedavisi ön plana çıkmaktadır ${ }^{3}$.

Çalışmada test edilen doripenem (DOR), TGC, minosiklin (MIN) ve amikasin (AK) Acinetobacter enfeksiyonlarının tedavisinde kullanılan ilaçlardır. TGC dışındakiler hem "Clinical and Laboratory Standards Institute (CLSI)" 2014 hem de "European Committee on Antimicrobial Susceptibility Testing (EUCAST)" 2017 rehberlerinde Acinetobacter türleri için önerilen antibiyotiklerdir. EUCAST ve CLSI rehberlerinde A.baumannii için sınır değeri bulunmayan TGC, A.baumannii'nin neden olduğu enfeksiyonların tedavisinde monoterapi veya kombine halde kullanılabilmektedir. Ancak son yıllarda, en iyi seçenekler olan kolistin (COL) ve TGC'ye karşı da direnç oranlarında artış saptanmaktadır ${ }^{4-6}$.

Üçüncü kuşak yeni bir sefalosporin olan seftolozanın, tazobaktam ile kombinasyonu olan seftolozan-tazobaktam (CT), Aralık 2014 tarihinde "Food and Drug Administration (FDA)" tarafından onaylanmış ve Zerbexa ismiyle klinik kullanıma girmiştir. Genişlemiş spektrumlu beta-laktamaz (GSBL) ve karbapenemaz üreten enterobakterilere; ÇiD Pseudomonas aeruginosa bakterilerine ve metronidazol ile kombine edildiğinde bazı anaerop bakterilere etkili olduğu bilinmektedir ${ }^{7}$. A.baumannii üzerinde CT'nin tek başına veya diğer ilaçlarla kombine edildiği az sayıda çalışma bulunmaktadır.

$\mathrm{Bu}$ çalışmanın amacı, YBÜ'lerde yatmakta olan hastalardan izole edilen ve enfeksiyon etkeni olduğu belirlenen, en az üç antibiyotik sınıfına dirençli A.baumannii izolatlarında DOR, TGC, MIN, AK ve yeni geliştirilen bir ilaç olan CT'nin duyarlılığını antibiyotik gradiyent test yöntemiyle belirlemek; sonrasında CT/DOR, CT/ TGC, CT/MIN ve CT/AK kombinasyonlarının in vitro etkinliğini aynı yöntemle araştırmaktır. Bu çalışma ile ÇiD A.baumannii izolatlarının neden olduğu enfeksiyonların tedavisinde yeni antibiyotiklere dikkat çekmek ve yeni tedavi protokollerinin geliştirilmesine katkıda bulunmak hedeflenmiştir.

\section{GEREÇ ve YÖNTEM}

Bu çalışma, Yüzüncü Yıl Üniversitesi Girişimsel Olmayan Klinik Araştırmalar Etik Kurul onayı ile gerçekleştirildi (Tarih: 02.12.2016 ve Karar no: B.30.2.YYU.0.01.00.00/123).

Ocak 2017-Temmuz 2017 tarihleri arasında YBÜ'lerde yatmakta olan hastaların mikrobiyoloji laboratuvarına gelen çeşitli klinik örneklerinden (kan, idrar, balgam, trakeal aspirat, yara, apse, kateter vb.) izole edilen, en az üç antibiyotik sınıfına (aminoglikozit, karbapenem, kinolon, kolistin ve/veya folat sentaz inhibitörleri) direnç gösteren ÇiD ve enfeksiyon etkeni olarak kabul edilen A.baumannii izolatları çalışmaya dahil edildi. İzolatların tümü 
farklı tarihlerde ve farklı birimlerde yatan hastalardan izole edilmiş olup her hastadan yalnız bir klinik izolat çalışmaya alındı. Çalışma süresi boyunca bu koşulları sağlayan ve antibiyotik profilleri farklılık gösteren klonal ilişkisi bilinmeyen toplam 35 izolat toplandı.

Örneklerden izole edilen koloniler Phoenix 100 BD (Becton Dickinson, ABD) otomatize sistemi ile tanımlandı. ÇiD izolatlarının seçilmesi için yapılan antibiyotik duyarlılık testi de aynı otomatize sistemle gerçekleştirilerek EUCAST önerilerine göre değerlendirildi. EUCAST rehberinde TGC'ye ait sınır değerler bulunmadığından TGC duyarlılığı FDA'nın Enterobacterales ailesi üyeleri için önerdiği $(\leq 2 \mu \mathrm{g} / \mathrm{ml}$ duyarlı ve $\geq 8 \mu \mathrm{g} / \mathrm{ml}$ dirençli) kriterlere göre değerlendirildi ${ }^{4}$.

Çalışmada kullanılan DOR, TGC, MIN ve AK'ın hem tek başına hem de CT ile ikili kombinasyonlarının (CT/DOR, CT/TGC, CT/MIN, CT/AK) minimum inhibitör konsantrasyonu (MiK) değerleri antibiyotik gradiyent test yöntemi ile değerlendirildi. Antibiyotik kombinasyonlarının (CT/DOR, CT/TGC, CT/MIN, CT/AK) etkileşimlerinin in vitro olarak belirlenmesinde fraksiyonel inhibitör konsantrasyon indeksi (FiKi) kullanıldı. Antibiyotik gradiyent yöntemiyle FiKi'nin belirlenmesi amacıyla öncelikle kombinasyonda yer alan iki farklı antibiyotiğin (A ve B antibiyotikleri) ayrı ayrı MiK değerleri tespit edildi. Daha sonra iki ilacın birlikte kullanıldığı durumlardaki Mik değerleri hesaplandı. Fraksiyonel inhibitör konsantrasyonu (FiK) A ve FiK B değerleri bulundu. FiKi= FiK A + FiK B olacak şekilde hesaplandı.

FiK $A=$ = B'nin varlığında A'nın MiK değeri/Tek başına A'nın MiK değeri

FiK $B=A^{\prime}$ nın varlığında B'nin MiK değeri/Tek başına B'nin MiK değeri

Elde edilen Fiki verilerine göre; FiKi $\leq 0.5$ ise sinerjik, $0.5<$ FiKi $\leq 1$ ise aditif, $1<$ FiKi $<2$ ise indiferan (tanımlanamayan etkileşim) ve $2 \leq$ Fiki ise antagonist etkileşim olarak değerlendirildi.

Kontrol suşları olarak Pseudomonas aeruginosa ATCC 27853 ve Escherichia coli ATCC 25922 kullanıldı.

\section{İstatistiksel Analiz}

Verilerin istatistiksel analizi Minitabv14 programında Z testi kullanılarak yapıldı ve $\mathrm{p}<$ 0.05 düzeyi anlamlı kabul edildi.

\section{BULGULAR}

Çalışma süresince yoğun bakım hastalarından izole edilen ÇiD 35 adet A.baumannii izolatının 22 (\%62.9)'si erkek, 13 (\%37.1)'ü kadın hastalardan izole edilmiştir. Klinik örnek tipine göre örneklerin çoğunluğunu derin trakeal aspirat, balgam ve kan örnekleri oluşturmaktadır. Örnek türlerinin dağılımı Tablo I'de verilmiştir.

A.baumannii klinik izolatlarında EUCAST tarafından önerilen antimikrobik ilaç gruplarından siprofloksasin, gentamisin, imipenem ve meropeneme \%100, netilmisine \%96.6, AK'a \%85.7, trimetoprim-sülfametoksazole \%48.5 oranlarında direnç saptanmıştır. 


\begin{tabular}{|ll|}
\hline \multicolumn{2}{l|}{ Tablo I. İzolatların Elde Edildiği Klinik Örneklerin Dağııımı } \\
\hline Örnek türü & İzolat sayısı (\%) \\
\hline Trakeal aspirat & $10(28.5)$ \\
Balgam & $8(22.8)$ \\
Kan & $7(20)$ \\
İdrar & $5(14.2)$ \\
Yara & $3(8.5)$ \\
Kateter & $2(5.7)$ \\
Toplam & $35(100)$ \\
\hline
\end{tabular}

\begin{tabular}{|c|c|c|c|c|c|c|c|c|c|c|c|c|c|c|c|c|c|c|c|}
\hline \multirow[b]{2}{*}{ Antibiyotikler } & \multicolumn{19}{|c|}{ MiK sonuçları $(\mu \mathrm{g} / \mathrm{ml})$} \\
\hline & $\stackrel{๊}{0}$ & 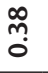 & $\stackrel{n}{0}$ & $\begin{array}{l}n \\
\hat{0}\end{array}$ & - & $\stackrel{n}{\sim}$ & $N$ & $m$ & $\nabla$ & 0 & $\infty$ & $\stackrel{\mathfrak{N}}{2}$ & $\stackrel{0}{-}$ & $\stackrel{\sim}{\sharp}$ & $\tilde{n}$ & $\stackrel{\infty}{+}$ & ఫै & 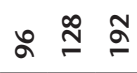 & ปู \\
\hline CT & & & & & & & & & & 1 & & 2 & 4 & 3 & 3 & 1 & 10 & 3 & 8 \\
\hline CT/AK & & & & & & 5 & & 1 & 1 & & 1 & 4 & 5 & 1 & 8 & 3 & 4 & & 2 \\
\hline $\mathrm{CT} / \mathrm{MIN}$ & & & & 2 & 2 & 3 & 1 & 6 & 5 & 1 & 5 & 10 & & & & & & & \\
\hline $\mathrm{CT} / \mathrm{TGC}$ & & & 1 & 1 & 3 & 5 & 16 & 9 & & & & & & & & & & & \\
\hline $\mathrm{CT} / \mathrm{DOR}$ & & & & & & & & & & & & 5 & 4 & 6 & 20 & & & & \\
\hline
\end{tabular}

CT için MiK değerlerinin $6 \mu \mathrm{g} / \mathrm{ml}$ ile $256 \mu \mathrm{g} / \mathrm{ml}$ arasında değiştiği ve $\mathrm{MiK}_{50} / \mathrm{MiK}_{90}$ değerinin 64/> $64 \mu \mathrm{g} / \mathrm{ml}$ olduğu belirlenmiştir. Kombine edilen diğer tüm antibiyotiklerin varlığında CT için $\mathrm{MiK}_{50} / \mathrm{MiK}_{90}$ değeri düşmüştür. Tüm izolatlara ait tek başına CT MiK değerleri ve bu değerlerin diğer antibiyotikler varlığındaki değişimi Tablo II'de gösterilmiştir. CT ile kombine edilen tüm antibiyotiklerin tüm izolatlara ait tek başına Mik değerleri ve bu değerlerin CT varlığındaki değişimleri Tablo III'te verilmiştir.

Çalışmaya dahil edilen 35 A.baumannii izolatına dört adet ikili antibiyotik kombinasyonu uygulanmış ve elde edilen 140 adet Fiki değeri sinerjik, aditif, indiferan ve antagonist şeklinde sınıflandırılmıştır. Antibiyotik kombinasyonlarına göre ortaya çıkan tüm etkileşim sonuçları ve oranları Tablo IV'te verilmiştir.

Etkileşim sonuçlarına bakıldığında en yüksek sinerjik etkileşim \%11.4 oranla CT/TGC arasında, daha sonra CT/AK (\%5.7) ve CT/MIN (\%5.7) kombinasyonlarında gözlenmiş̧ir. CT/DOR antibiyotikleri arasında ise sinerjik etkileşim gözlenmemiştir. Etkileşimlerin çoğu indiferan olarak tanımlanmıştır. Antagonist etkileşim yalnız CT/DOR kombinasyonunda (\%71.4) gözlenmiştir. CT/AK, CT/MIN ve CT/TGC kombinasyonlarında antagonist etkileşime rastlanmamıştır. 


\begin{tabular}{|c|c|c|c|c|c|c|c|c|c|c|c|c|c|c|c|c|c|c|c|c|c|}
\hline \multirow[b]{2}{*}{ Antibiyotikler } & \multicolumn{21}{|c|}{ Mik sonuçları $(\mu \mathrm{g} / \mathrm{ml})$} \\
\hline & $\stackrel{n}{\sim}$ & 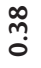 & $\ddot{n}$ & $\stackrel{n}{\kappa}$ & - & $\stackrel{n}{r}$ & N & $m$ & $\nabla$ & $\bullet$ & $\infty$ & $\stackrel{\simeq}{\simeq}$ & $\stackrel{0}{\leftarrow}$ & $\stackrel{\sim}{N}$ & $\stackrel{N}{m}$ & $\stackrel{\infty}{+}$ & ปั & ๙̊ & $\stackrel{\text { I্ }}{\square}$ & $\stackrel{\text { ๙ }}{\sigma}$ & ฝ̊ \\
\hline DOR & & & & & & & & & & & & & & & 35 & & & & & & \\
\hline $\mathrm{CT} / \mathrm{DOR}$ & & & & & & & & & & & 1 & & 5 & 3 & 26 & & & & & & \\
\hline TGC & & & & 2 & 5 & 17 & 7 & 4 & & & & & & & & & & & & & \\
\hline $\mathrm{CT} / \mathrm{TGC}$ & 1 & 1 & 1 & 2 & 7 & 11 & 11 & 1 & & & & & & & & & & & & & \\
\hline MIN & & 1 & 2 & 1 & 1 & 6 & 3 & 4 & & 4 & 8 & 4 & 1 & & & & & & & & \\
\hline CT/MIN & & & 2 & 3 & 4 & 2 & 6 & 4 & 1 & 6 & 6 & 1 & & & & & & & & & \\
\hline AK & & & & & 1 & & 5 & & & & & & 1 & & & & 2 & 6 & 5 & & 15 \\
\hline CT/AK & & & & & 1 & 3 & 2 & & & 1 & 3 & 3 & 5 & 1 & 4 & 5 & 5 & 1 & 1 & & \\
\hline
\end{tabular}

\begin{tabular}{|c|c|c|c|c|c|}
\hline \multirow{2}{*}{$\begin{array}{l}\text { Antibiyotik } \\
\text { kombinasyonu }\end{array}$} & \multicolumn{5}{|c|}{ Sayı (n) (\%) } \\
\hline & Sinerjik & Aditif & İndiferan & Antagonist & Toplam \\
\hline CT/DOR & $0(0)$ & $0(0)$ & $10(28.5)$ & $25(71.4)$ & 35 (100) \\
\hline CT/TGC & $4(11.4)$ & $9(25.7)$ & $22(62.8)$ & $0(0)$ & $35(100)$ \\
\hline CT/MIN & $2(5.7)$ & $16(45.7)$ & $17(48.5)$ & $0(0)$ & $35(100)$ \\
\hline CT/AK & $2(5.7)$ & $21(60)$ & $12(34.2)$ & $0(0)$ & $35(100)$ \\
\hline
\end{tabular}

İstatistiksel açıdan değerlendirildiğinde; sinerjik etki için TGC ile yapılan kombinasyonda DOR ile yapılan kombinasyona göre anlamlı fark tespit edilmiş olup, diğer antibiyotikler arasında anlamlı fark bulunamamıştır. Antagonist etki için DOR ile yapılan kombinasyon diğer antibiyotiklerle yapılan kombinasyonlara göre anlamlı bulunmuştur.

\section{TARTIŞMA}

YBÜ’ler dirençli bakterilerin ortaya çıkması ve yayılması için en uygun ortamlardır ${ }^{8}$. A.baumannii özellikle YBÜ'lerde görülen nozokomiyal enfeksiyonlardan en sık izole edilen bakterilerdendir ${ }^{9}$. A.baumannii'nin etken olarak izole edildiği klinik örnekler farklılık göstermektedir. Çalışmamızda literatürle uyumlu şekilde 35 izolatın \%51.3'ü derin trakeal aspirat ve balgam gibi solunum sistemi örneklerinden izole edilmiştir ${ }^{4}$.

Son zamanlarda Acinetobacter türlerinde görülen ÇiD, mevcut tedavi seçeneklerini kısıtlamaktadır. Eroğlu ve arkadaşları 2006-2011 yıllarını kapsayan çalışmalarında ${ }^{10}$ izole ettikleri 3212 adet Acinetobacter spp. izolatında test edilen antibiyotikler ve direnç yüzdelerini; imipenem \%77.2, meropenem \%77, siprofloksasin \%78.9 ve TGC \%5.9 
olarak bulmuşlardır. Cesur ve arkadaşları ${ }^{4}$ A.baumannii izolatlarında TGC (\%6) dışındaki antibiyotik gruplarına yüksek oranda direnç saptamışlardır. Duman ve arkadaşları dört yılı kapsayan çalışmalarında ${ }^{11}$ ÇiD A.baumannii izolatlarında TGC direncini 2011 yılında \%4, 2015 yılında ise \%16 olarak bulmuşlar ve tedavide halen etkin bir antimikrobiyal ilaç olduğunu vurgulamışlardır. Çalışmamızda siprofloksasin, gentamisin, imipenem ve meropeneme $\% 100$, netilmisine $\% 96.6$, AK'a \%85.7, trimetoprim-sülfametoksazole $\% 48.5$ oranında direnç saptanmış olup TGC direncine rastlanmamıştır. Çalışmanın ÇiD izolatlarında yapılmış olması direnç oranlarımızın yüksek çıkmasına neden olmuş olabilir.

Seftolozan, mevcut bir beta-laktamaz inhibitörü olan tazobaktam ile kombine edilen ve ÇiD organizmalara karşı aktivite gösteren yeni bir üçüncü kuşak sefalosporindir ${ }^{12,13}$. Farrell ve arkadaşları 2012 yılında yaptıkları bir çalışmada ${ }^{14} 233$ adet A. baumannii izolatında, CT'nin MiK $_{50} /$ MiK $_{90}$ değerlerini 32/> $32 \mu \mathrm{g} / \mathrm{ml}$ bulmuş ve ÇiD aerobik gram-negatif bakteriler için değerli bir tedavi seçeneği olabileceğini ileri sürmüşlerdir. Sader ve arkadaşları ${ }^{15} 2012$ yılında yaptıkları çalışmada A.baumannii izolatlarında ilacın $\mathrm{MiK}_{50} / \mathrm{MiK}_{90}$ değerini $16 />32 \mu \mathrm{g} / \mathrm{ml}$, Dobias ve arkadaşları ${ }^{16}$ ise $16 />64 \mu \mathrm{g} / \mathrm{ml}$ olarak saptamışlar ve sınırlı sayıdaki A.baumanni'ye değişken etki gösterdiği kanısına varmışlardır. Hsueh ve arkadaşları $^{17} 100$ adet imipeneme dirençli A.baumannii izolatında antibiyotik MiK $_{90}$ değerini $>64 \mu \mathrm{g} / \mathrm{ml}$ olarak bularak ilacın Acinetobacter enfeksiyonlarına yeterli düzeyde etki etmediği sonucuna varmışlardır. Çalışmamızda CT için MiK değerleri $6 \mu \mathrm{g} / \mathrm{ml}$ ile $256 \mu \mathrm{g} /$ $\mathrm{ml}$ arasında değişmekte olup $\mathrm{MiK}_{50} / \mathrm{MiK}_{90}$ değeri literatürle uyumlu olarak 64/> $64 \mu \mathrm{g} / \mathrm{ml}$ olarak bulunmuş ve tek başına yeterli etkinliği sağlayamadığı kanısına varılmıştır.

Literatürde Acinetobacter türleri üzerinde CT ile DOR, TGC, MIN ve AK'ı kombine eden çalışma bulunamamıştır ancak diğer bakteriler üzerinde bu antibiyotikle yapılmış kombinasyon çalışmaları mevcuttur. Jackualine ve arkadaşları 2017 yılında yaptıkları çalışmada ${ }^{18}$ P.aeruginosa, GSBL üreten E.coli ve Klebsiella pneumoniae izolatlarında CT ile aztreonam, AK, TGC ve meropenemi kombine etmiş; meropenem ve AK ile sinerjik etkileşim saptamışlardır. Dassner ve arkadaşları ${ }^{19}$ 2014-2016 yıllarında ÇiD P.aeruginosa izolatları üzerinde CT ile AK ve tobramisini kombine etmiş ve CT/AK kombinasyonunun tobramisinden daha faydalı olduğu sonucuna varmışlardır. Smith ve arkadaşları ${ }^{20}$ ise 2016 yılında metisiline dirençli Staphylococcus aureus (MRSA) izolatlarında CT ile daptomisini kombine etmişler ve $\mathrm{CT}^{\prime}$ nin daptomisin ile birlikte verildiğinde daptomisinin MRSA'ya karşı aktivitesini arttırdığı sonucuna varmışlardır.

Çalışmamızda tek başına TGC'nin ÇiD A.baumannii enfeksiyonlarının tedavisinde etkili bir tedavi seçeneği olduğu; MIN ve DOR'un ise tek başına etkili olmadığı kanısına varılmıştır. Ayrıca CT/TGC kombinasyonunda dört, CT/MIN ve CT/AK kombinasyonlarında ikişer izolatta sinerjik etkileşim görülmüştür. DOR'un CT ile kombinasyonunda yüksek oranda antagonistik etkileşim saptanmıştır.

Sonuç olarak çalışmamız, yeni bir beta-laktam/beta-laktamaz inhibitörü olan CT'nin, tek başına A.baumannii izolatlarına yeterli etki etmediği ancak sinerjik etkileşim gözle- 
nen kombinasyonların bir tedavi seçeneği olabileceği düşünülmüştür. CT'nin DOR ile saptanan antagonist etkileşimi nedeniyle klinik kullanımda dikkatle izlenmelidir. Acinetobacter türleri ve ÇiD diğer bakteriler üzerinde CT ile yapılmış çok az sayıda kombinasyon çalışması mevcuttur. Bu tür çalışmaların artırılması klinisyenlere farklı tedavi seçenekleri sunacak, sağkalımın artırılması ve ölüm oranlarının azaltılması açısından yüz güldürücü sonuçlara neden olacaktır.

\section{ÇIKAR ÇATIŞMASI}

Yazarlar bu makale ile ilgili herhangi bir çıkar çatışması bildirmemişlerdir.

\section{KAYNAKLAR}

1. Viehman JA, Nguyen MH, Doi Y. Treatment options for carbapenem-resistant and extensively drug-resistant Acinetobacter baumannii infections. Drugs 2014;74(12):1315.

2. Tünay H, Demirdal T, Demirtürk N. Acinetobacter enfeksiyonlarında dirençle ilgili değişen tanımlamalar ve dirençte güncel durum. Türk Mikrobiyol Cem Derg 2012;42(4):123-6.

3. Nation RL, Garonzik SM, Li J, Thamlikitkul V, Giamarellos EJ, Paterson DL. Updated US and European dose recommendations for intravenous colistin: How do they perform? Clin Infect Dis 2016;62(5):552-8.

4. Cesur S, Irmak H, Yalçın AN, Berktaş M, Baysan BÖ, Kınıklı S. Yoğun bakım ünitesinde yatan hastaların çeşitli kültür örneklerinden izole edilen Acinetobacter baumannii suşlarının antibiyotik duyarlılıkları. Ortadoğu Tıp Dergisi 2017; 9(2):51-5.

5. Kınıkı S, Cesur S, Yücel M, Hatipoğlu ÇA, Dinç B. Determination of polymyxin B, minocycline, colistin and phosphomycin susceptibilities in Acinetobacter baumannii strains showing carbapenem resistant multidrug resistance phenotype. J Health Sci Med 2019;2(2):49-53.

6. http://www.eucast.org/clinical_breakpoints/ (Erişim tarihi: 02.08.2017).

7. Elaldı N. Ufuktaki yeni antibiyotikler. FLORA 2015;20(1):1-9.

8. Şahintürk H, Özdemirkan A, Kılıç F, Özalp O, Arslan H, Zeyneloğlu P. Cerrahi yoğun bakım hastalarında çoklu ilaç dirençli enfeksiyonların mortalite üzerine etkisi. J Turk Soc Intensive Care 2018;16(2):58-63.

9. Şirin MC, Ağuş N, Yılmaz N, Bayram A, Yılmaz S, şamlığlu P. Yoğun bakım ünitelerinde yatan hastaların kan kültürlerinden izole edilen mikroorganizmalar ve antibiyotik duyarlııkları. Turk Hij Den Biyol Derg 2017;74(3):269-78.

10. Eroğlu C, Ünal N, Karadağ A, Yılmaz H, Acuner iç, Günaydın M. Çeşitli klinik örneklerden 2006-2011 yılları arasında izole edilen Acinetobacter türleri ve antibiyotik duyarlııkları. Turk Hij Den Biyol Derg 2016;73(1):2532.

11. Duman $Y$, Kuzucu C, Tekerekoglu MS. Comparison of minimal inhibitory concentrations (MICs) of tigecycline in 2011 and 2015 years against multidrug-resistance Acinetobacter baumannii strains. Med Science 2017;6(1):26-9.

12. Liscio JL, Mahoney MV, Hirsch EB. Ceftolozane/tazobactam and Ceftazidime/avibactam: two novel beta-lactam/beta-lactamase inhibitor combination agents for the treatment of resistant gram-negative bacterial infections. Int J Antimicrob Agents 2015;46(3):266-71.

13. Akbal AU, Çoban AY, Durupınar B. Yeni antibakteriyeller. Türk Mikrobiyol Cem Derg 2018;48(2):87-99.

14. Farrell DJ, Sader HS, Flamm RK, Jones RN. Ceftolozane/tazobactam activity tested against gram-negative bacterial isolates from hospitalised patients with pneumonia in US and European medical centres (2012). Int J Antimicrob Agents 2014;43(6):533-9.

15. Sader HS, Farrell DJ, Flamm RK, Jones RN. Ceftolozane/tazobactam activity tested against aerobic gram-negative organisms isolated from intra-abdominal and urinary tract infections in European and United States hospitals (2012). J Infect 2014;69(3):266-77. 
16. Dobias J, Dénervaud-Tendon V, Poirel L, Nordmann P. Activity of the novel siderophore cephalosporin cefiderocol against multidrug-resistant gram-negative pathogens. Eur J Clin Microbiol Infect Dis 2017;36(12):2319-27.

17. Hsueh SC, Lee YJ, Huang Y, Liao CH, Tsuji M, Hsueh PR. In vitro activities of cefiderocol, ceftolozane/tazobactam, ceftazidime/avibactam and other comparative drugs against imipenem-resistant Pseudomonas aeruginosa and Acinetobacter baumannii, and Stenotrophomonas maltophilia, all associated with bloodstream infections in Taiwan. J Antimicrob Chemother 2019;74(2):380-6.

18. Jacqueline C, Howland K, Chesnel L. In vitro activity of ceftolozane/tazobactam in combination with other classes of antibacterial agents. J Glob Antimicrob Resist 2017;10:326-9.

19. Dassner AM, Sutherland C, Girotto J, Nicolau DP. In vitro activity of ceftolozane/tazobactam alone or with an aminoglycoside against multi-drug-resistant Pseudomonas aeruginosa from pediatric cystic fibrosis patients. Infect Dis Ther 2017;6(1):129-36.

20. Smith JR, Arya A, Yim J, Barber KE, Hallesy J, Singh NB, Rybak MJ. Daptomycin in combination with ceftolozane-tazobactam or cefazolin against daptomycin-susceptible and-nonsusceptible Staphylococcus aureus in an in vitro, hollow-fiber model. Antimicrob Agents Chemother 2016;60(7):3970-5. 